\title{
Supraclavicular Artery Island Rotational Flap in Reconstruction of Parotid Area Surgical Defect
}

\author{
Zahraa Mohamed Nasreldin, Tilal Salaheldin, Safa Abdelazim, Ahmed M Suliman and Yousif I Eltohami* \\ Suba Teaching Hospital Department of Oral and Maxillofacial Surgery, Sudan
}

Submission: May 29, 2020; Published: June 04, 2020

*Corresponding author: Yousif Altohami, Department of Oral and Maxillofacial Surgery, Faculty of Dentistry, University of Khartoum, Sudan

Abstract

The supraclavicular artery island flap is a fasciocutaneous flap harvested from the supraclavicular and deltoid regions, blood supply of this flap is derived from the supraclavicular artery, a direct cutaneous branch of the transverse cervical artery in $93 \%$ of cases or the supraclavicular artery in 7\% of cases. A 66 years male diagnosed of Mucoepidermoid Carcinoma of the right parotid gland with positive regional lymph nodes involvement presented to Suba Teaching Hospital and managed by a supra-omohyoid selective neck dissection and the supraclavicular artery island flap was used to restore the defect caused by the surgical excision of the tumor.

Keywords: Supraclavicular Artery Island Flap (SCAIF); Mucoepidermoid Carcinoma (MEC); Supra-omohyoid Neck dissection

Abbreviations: SCAIF: Supraclavicular Artery Island Flap; MEC: Mucoepidermoid Carcinoma; SAI: Supraclavicular Artery Island

\section{Introduction}

The supraclavicular artery island (SAI) flap is a local fasciocutaneous flap taken from skin on the shoulder and supraclavicular area. It is becoming popular for reconstruction of head and neck defects. The application of such flap to the head and neck has evolved and has been controversial at times with respect to its vascularity and reliability [1]. This pedicled flap is thin, malleable, easily, and rapidly harvested with a reliable pedicle and minimal donor site morbidity. It can be used for onestep innervated reconstruction of many types of head and neck defects such as tracheal-stomal, mandible, intra-oral, parotid, neck (e.g. exposed carotid arteries), pharyngeal wall, skull base and cutaneous facial defects. It constitutes an alternative to local flaps providing equivalent functional results and must be an integral part of the cancer surgeon's therapeutic armamentarium [2]. The SAI flap is found to be most similar to the radial forearm flap with respect to thickness and pliability of the skin in thin patients. In patients with a larger body habitus, the skin might have been more similar to that of an ALT myocutaneous flap. For cervicofacial defects, the SAI flap is believed to be advantageous to cervicofacial advancement in larger defects or in patients who had received prior radiotherapy. The top of the auricle could generally be reached with the flap in cases of temporal bone or parotidectomy defects and the latest was what had happened in this case [1].
Mucoepidermoid carcinoma (MEC) is the most common malignancy of the major and minor salivary glands, comprising $34 \%$ of salivary gland malignancies [2]. It has a female preponderance, with a prevalence that is highest in the fifth decade of life [3]. Its clinical behavior is highly variable and ranges from slow-growing and indolent to locally aggressive and highly metastatic. Histologically, MEC is comprised of 3 different cell types: mucinous cells, intermediate cells, and epidermoid cells. Growth patterns range from cystic to solid to infiltrative. These parameters have been incorporated into several different grading systems that have been correlated with prognosis and therefore play an important role in treatment decisions. Most grading systems for MEC are classifying tumors into low, intermediate, and high grade. Low-grade tumors are well-demarcated, with pushing margins and dilated cystic areas containing mucinous material. The cysts are formed by mucinous and intermediate cells. Lowgrade histopathology is defined by its lack of aggressive invasion pattern [4]. Surgical resection is the mainstay of treatment for all grades of MEC. Local resection of the cancer is considered sufficient treatment for low-grade tumors. High-grade tumors are generally treated with surgical excision with wide margins followed by postoperative radiotherapy. Neck dissection is often used when regional metastasis is present. Elective neck dissection has been used for high-grade cancers. Intermediate-grade MEC treatment 
varies from local excision to wide excision with lymphadenectomy and/or postoperative radiotherapy [4].

\section{Case Report}

A 66 years old male reported to Soba Teaching Hospital complaining of swelling on the right side of the face, started 20 years ago as a painless mass in the prearicular area and gradually increased in size, became ulcerated 3 months ago. No abnormalities mentioned according to past medical history. He had history of smoking 42 years ago that lasted for 2 months in duration and a frequency of 15 cigarettes per day.

\section{On Examination}

An Ulcerative nodular swelling measuring $12 \times 9 \mathrm{~cm}$ in right side of the face elevating the ear lobe , anatomically extending from the zygomatic arch superiorly to the submandibular area inferiorly, anteriorly $4 \mathrm{~cm}$ away from right commissure (Figure 1), posteriorly extending $2 \mathrm{~cm}$ in the post-auricular area with no paresthesia or tenderness. Facial nerve is intact (Figure 2). Both the Left and right submandibular lymph nodes were palpable and mobile measuring $1 \times 1$ in $\mathrm{cm}$ as well as the submental lymph node being palpable, firm, and mobile measuring about $3 \mathrm{~cm}$. the right jugulodigastric was also palpable and mobile.

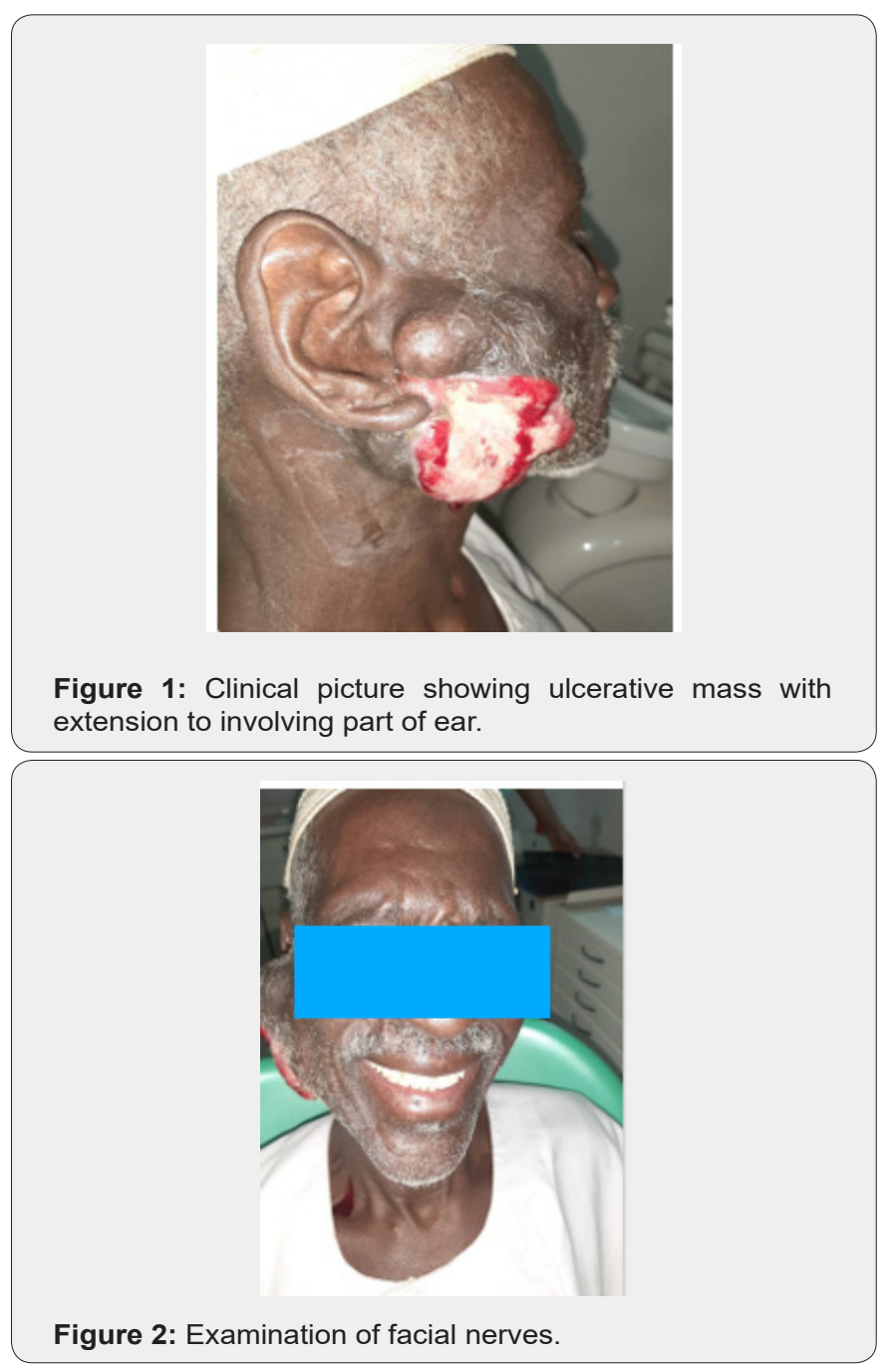

\section{Investigations}

i. Incisional biopsy for histopathological diagnosis revealed an intermediate grade Mucoepidermoid Carcinoma.

ii. Complete work panel.

iii. Viral screening was negative for HIV, HBV and HCV.

iv. Contrast-enhanced CT-Scan (Figure 3) revealed a mass in parotid involving both the superficial and deep lobes with calcification due to long standing of the tumor

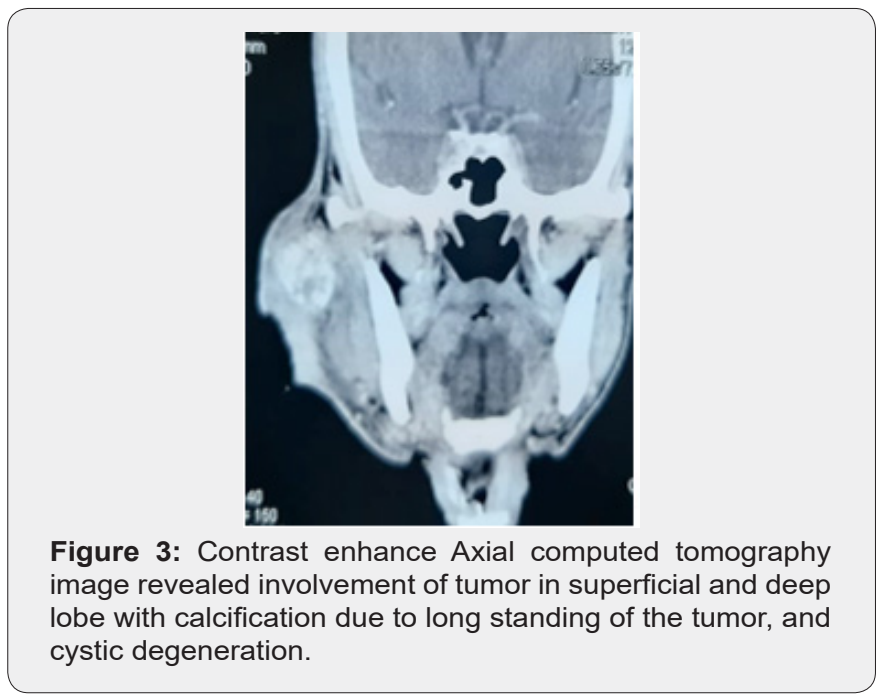

\section{v. Chest x-ray. \\ vi. ECG Echocardiogram. \\ vii. Abdominal ultrasound}

A consent was agreed upon by the patient with complete discussion and detail of the treatment plan.

\section{Treatment}

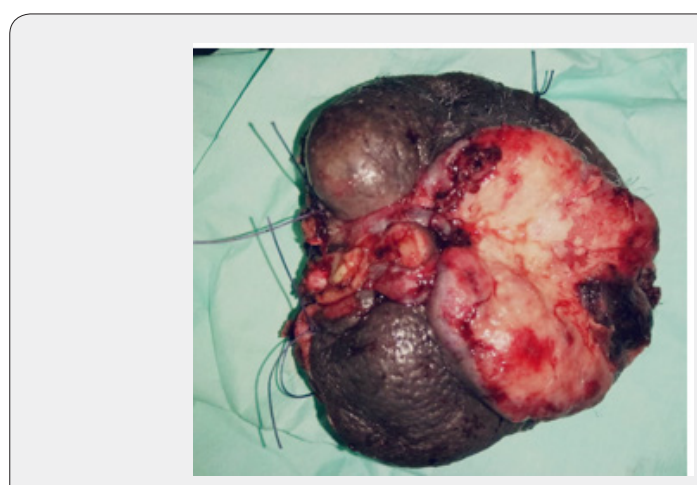

Figure 4: showed tumor after resection (total parotidectomy with part of ear Pena)

In the maximum possible aseptic conditions under general anesthesia with oral intubation, scrubbing and draping was done. Extended right supraomohyoid neck dissection with total Parotidectomy (Figure 4). Landmarks were drawn for lesion and neck dissection then local anesthesia applied, Neck dissections was performed, excision of superficial and deep lobe of parotid 
with part of ear Pinna and lobule with facial nerve sacrification were carried out. Hemostasis was obtained and incision of neck dissection was sutured.

\section{Reconstruction with supraclavicular artery island rotational flap}

Defect site was measured in length and width, then the flap was designed on the patient's shoulder extending anteriorly to the clavicle, posteriorly to the trapezius muscle and laterally to the deltoid muscle. The flap was raised in a suprafascial plane from distal to until the supraclavicular vascular pedicle was identified. At the clavicle, dissection was slowed and moved to subfascial plane to improve arch of rotation. Distal tip of the flap was trimmed where necessary until healthy bleeding was seen, proximal flap was de-epithelialized. A surgical Hemovac Drain was applied to help eliminate dead space as well as preventing potential accumulation of fluid. The Patient had received 4 units of blood with 8 fresh frozen plasma units. Patient recovered well (Figure 5). Total parotidectomy with selective neck dissection supraomohyoid and supraclavicular artery island rotational flap used for reconstruction. Facial nerve was sacrificed during surgery, part of ear Pena's was resected due to its involvement by the tumor. Ulcerative skin was excised with safety margins. Excisional biopsy revealed mucoepidermoid carcinoma intermediate grade with reactive lymph nodes (Figure 6). Follow up was done daily with dressing until patient was discharged and then he was checked weekly. Flap is vital, healing is very good. Operated by last author (Figure 7).

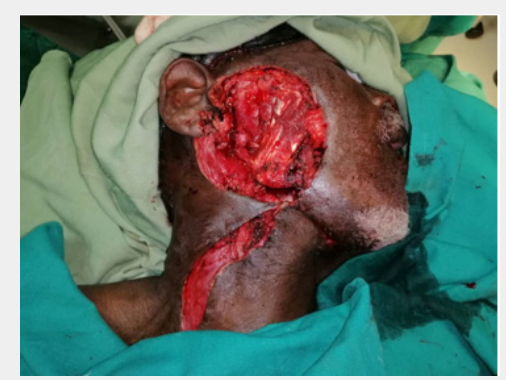

Figure 5: Extended supra-omohyoid neck dissection with removal of parotid gland and part of ear.

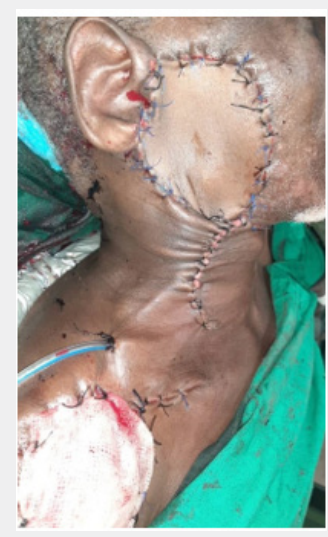

Figure 6: Patient immediately after surgery.

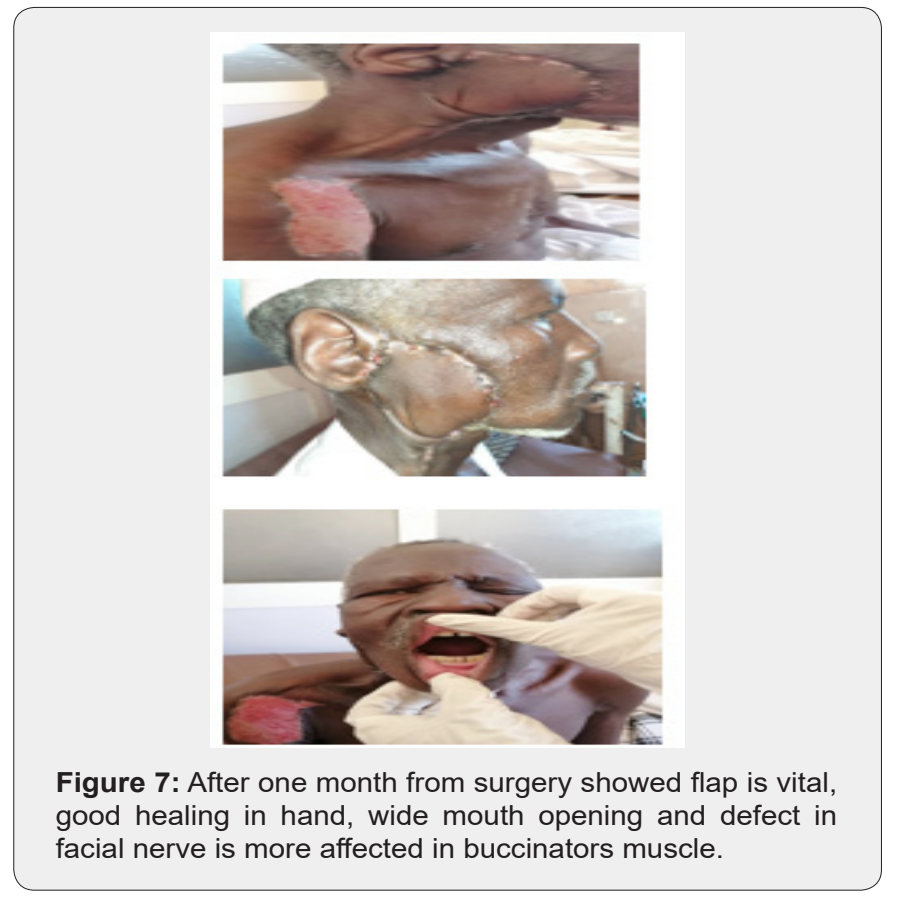

\section{Discussion}

Mucoepidermoid carcinoma accounts for less than 10\% of all tumors of the salivary gland, it constitutes approximately $30 \%$ of all malignant tumors of the salivary gland and occurs most frequently in the parotid gland [5]. Intermediate cells are thought to be capable of differentiating into mucous or epidermoid cells. As a result of this cellular heterogeneity, the histologic composition, biological behavior, and clinical course of MEC varies. Stewart and colleagues defined benign and malignant varieties of mucoepidermoid tumors [6]. Nonetheless, subsequent metastases of a few of the previously benign tumors has led to all mucoepidermoid tumors being considered carcinoma, they can recur, and they can metastasize to regional lymph nodes or distant viscera [7]. Patients with low- and intermediate-grade MEC had significantly better overall survival and disease-free survival than patients with high-grade disease, but no difference in survival rates was found between low- and intermediate-grade diseases. Pathologic results of positive lymph nodes, extracapsular lymph node spread, and perineural invasion were all found to be poor prognostic indicators according to the study at the University of Texas MD Anderson Cancer Center [8].

For many years, reconstructive surgeons used regional flaps, such as the pectoralis major myocutaneous, trapezius, latissimus dorsi, or deltopectoral flaps for closure of oncologic defects. Although these regional flaps are easy to harvest and very reliable, they are not ideal. Regional flaps are often bulky and lead to significant donor-site morbidity from a functional and aesthetic perspective. When used for skin resurfacing, distant tissue provides a poor color match. However, free-tissue transfer requires specialized expertise that may not be readily available in all centers, longer operative times, and extensive postoperative monitoring [1]. Selection of SCAIF over other reconstructive 


\section{Advances in Dentistry \& Oral Health}

options such as mircrovascular free-tissue-transfer flaps is the best option for reconstruction of head and neck area despite being reliable and offers most versatility but requires more operation time and technical expertise, SCAIF is preferred more than regional flaps e.g. deltopectoral flap (due to short length can't reach parotid area) and the pectoralis major (are reliable, versatile, requires short time operations, however is often bulky and color don't match and it has high prevalence of morbidity and flap necrosis) in contrast, SCAIF is thin, pliable and hairless, providing a valid alternative for reconstruction of oral and oropharyngeal defects and applicable for parotid area $[1,9,10-12]$.

This particular flap was selected because it offers a series of advantages: flap harvesting is easy and quick and does not require microsurgical expertise. Vascular micro sutures needed during free tissue transfer are time-consuming and expose the patient to eventual thrombotic complications of the anastomoses. From experienced surgeons, SCAIF harvesting time is less than 1h, Comparable harvesting times are reported in the literature $[9,10,13]$. SCAIF is high versatile, provides a good esthetic results and matching color. Similar applications are described in many studies [9-18]. In the above-mentioned case part of the tumor was spreading to the ear Pinna, it was removed simultaneously with the tumor and reconstructed by part of the SCAIF $[19,20]$. Caution and consideration for pre-operative imaging of patients with prior level V neck dissections because extension to this level will injured the transverse cervical artery which supply SCAIF or use of contralateral shoulder in the setting of prior radiation, to avoid such an injury extended supraomohyoid neck dissection with vertical incision was selected over other incision techniques such as the Apron Incision preventing the loss of the upper part of skin and thus, a risk of necrosis. Follow up was done daily for one week then patient discharged on medications and came for dressing, his healing is good now and hearing is intact, he was complaining from muscle stretching therefore, muscle relaxant as well as analgesic was prescribed, tension became more better by time. Pt was referred to oncology department for adjuvant radiotherapy. There are many factors that affect the prognosis of MEC mainly, the clinical stage and histological grade and overall, 5 years survival rate varies from $62 \%$ to $92 \%$ in intermediate-grade tumor as mentioned in literature [21].

\section{Conclusion}

In this initial experience, the SAIF is advantageous for the following reasons. First, harvesting the flap is simple and can be accomplished in less than 1 hour. Second, the skin is thin and pliable and provides an excellent color match for cervical and facial defects. The length of the flap is sufficient to reach many defects in different head and neck locations.

\section{References}

1. Kokot N, Mazhar K, Reder LS (2013) The supraclavicular artery island flap in head and neck reconstruction. Applications and limitations. JAMA Otolaryngol Head Neck Surg 139(11): 1247-1255.

2. Atallah S (2015) Supraclavicular Artery Island Flap in Head and Neck
Reconstruction. European Annals of Otorhinolaryngology, Head and Neck Diseases 132(5): 291-294.

3. Spiro RH (1986) Salivary neoplasms: overview of a 35-year experience with 2,807 patients. Head Neck Surg 8(3): 177-184.

4. Thompson LD (2005) Mucoepidermoid carcinoma. Ear Nose Throat J 84(12): 762-763.

5. Nance, Melonie A (2008) Treatment and Survival Outcomes Based on Histologic Grading in Patients with Head and Neck Mucoepidermoid Carcinoma. Cancer 113(8): 2082-2089.

6. Cornog JL, Gray SR (1976) Surgical and clinical pathology of salivary gland tumors. In: Rankow M, Polayes IM, eds. Disease of the Salivary Glands. Philadelphia, Pa: WB Saunders Co pp. 99-142.

7. Stewart FW, Foote FW, Becker WF (1945) Muco-epidermoid tumors of salivary glands. Ann Surg 122: 820-844.

8. McHugh CH (2012) Prognostic factors in mucoepidermoid carcinoma of the salivary glands. Cancer 118(16): 3928-3936.

9. Foote FW, Frazell EL (1953) Tumors of the major salivary glands Cancer 6(6): 1065-1133.

10. Alves HR, Ishida LC, Ishida LH (2012) A clinical experience of the supraclavicular flap used to reconstruct head and neck defects in latestage cancer patients. J Plast Reconstr Aesthet Surg 65: 1350-1356.

11. Chen WL, Zhang DM, Yang ZH, Zhi Quan Huang, Jian Guang Wang, et al. (2010) Extended supraclavicular fasciocutaneous island flap based on the transverse cervical artery for head and neck reconstruction after cancer ablation. J Oral Maxillofac Surg 68(10): 2422-2430.

12. Wu H, Chen WL, Yang ZH (2012) Functional reconstruction with an extended supraclavicular fasciocutaneous island flap following ablation of advanced oropharyngeal cancer. J Craniofac Surg 23(6): 1668-1671.

13. Anand AG, Tran EJ, Hasney CP (2012) Oropharyngeal reconstruction using the supraclavicular artery island flap: a new flap alternative. Plast Reconstr Surg 129(2): 438-441.

14. Welz C, Canis M, Schwenk-Zieger S (2017) Oral cancer reconstruction using the supraclavicular artery island flap: comparison to free radial forearm flap. J Oral Maxillofac Surg 75(10): 2261-2269.

15. Chiu ES, Liu PH, Friedlander PL (2009) Supraclavicular artery island flap for head and neck oncologic reconstruction: indications, complications, and outcomes. Plast Reconstr Surg 124(1): 115-123.

16. Sands TT, Martin JB, Simms E (2012) Supraclavicular artery island flap innervation: anatomical studies and clinical implications. J Plast Reconstr Aesthet Surg 65(1): 68-71.

17. Kim RJT, Izzard ME, Patel RS (2011) Supraclavicular artery island flap for reconstructing defects in head and neck region. Curr Opin Otolaryngol Head Neck Surg 19(4): 248-250.

18. Sandu K, Monnier P, Pasche P (2012) Supraclavicular flap in head and neck reconstruction: experience in 50 consecutive patients. Eur Arch Otorhinolaryngol 269: 1261-1267.

19. Granzow JW, Suliman A, Roostaeian J (2013) The supraclavicular artery island flap (SCAIF) for head and neck reconstruction: surgical technique and refinements. Otolaryngol Head Neck Surg 148(6): 933940.

20. Giordano L, Bondi S, Toma S (2014) Versatility of the supraclavicular pedicle flap in head and neck reconstruction. Acta Otorhinolaryngol Ital 34(6): 394-398.

21. Hicks M, Jel-Naggar AK, Flaitz CM, Luna MA, Batsakis JG, et al. (1995) Histocytologic grading of mucoepidermoid carcinoma of major salivary glands in prognosis and survival: a clinicopathologic and flow cytometric investigation. Head Neck 17(2): 89-95. 

(CC) Commons Attribution 4.0 License

DOI: 10.19080/ADOH.2020.12.555844

\section{Your next submission with Juniper Publishers} will reach you the below assets

- Quality Editorial service

- Swift Peer Review

- Reprints availability

- E-prints Service

- Manuscript Podcast for convenient understanding

- Global attainment for your research

- Manuscript accessibility in different formats

( Pdf, E-pub, Full Text, Audio)

- Unceasing customer service

Track the below URL for one-step submission https://juniperpublishers.com/online-submission.php 